\title{
Evasion of Intracellular DNA Sensing by Human Herpesviruses
}

\author{
Debipreeta Bhowmik and Fanxiu Zhu* \\ Department of Biological Science, Florida State University, Tallahassee, FL, United States
}

Sensing of viral constituents is the first and critical step in the host innate immune defense against viruses. In mammalian cells, there are a variety of pathogen recognition receptors (PRRs) that detect diverse pathogen-associated molecular patterns (PAMPs) including viral RNA and DNA. In the past decade, a number of host DNA sensors have been discovered and the underlying sensing mechanisms have been elucidated. Herpesviruses belong to a large family of enveloped DNA viruses. They are successful pathogens whose elaborate immune evasion mechanisms contribute to high prevalence of infection among their hosts. The three subfamilies of herpesviruses have all been found to employ diverse and overlapping strategies to interfere with host DNA sensing. These strategies include masking viral DNA or the DNA sensor, degradation of the DNA sensor, and posttranscriptional modification of the DNA sensor or its adaptor protein. In this review, we will discuss the current state of our knowledge on how human herpesviruses use these strategies to evade DNA-induced immune responses. Comprehensive understanding of herpesvirus immune-evasion mechanisms will aid in the development of vaccines and antivirals for herpesvirus-associated diseases.

Keywords: cGAS, DNA sensing, innate immune response, herpesvirus, viral evasion

\section{INTRODUCTION}

Herpesviruses belong to a family of large DNA viruses that characteristically cause both latent and lytic infections in a wide range of animals and humans. There are eight types of herpesviruses currently known to infect humans, causing various diseases (Knipe and Howley, 2013). Herpesviruses are subdivided into the $\alpha_{-}, \beta$-, and $\gamma$-subfamilies, based on biologic properties including cell tropism, genome organization, and sequence homologies of the conserved openreading frames (ORFs) (Davison et al., 2009) (Table 1).

The host innate immune response is the first line of defense against viral infection. It is activated by the host pattern recognition receptors (PRRs) upon detecting conserved molecular moieties from the pathogens, known as Pathogen Associated Molecular Pattern (PAMPs) (Mogensen, 2009). Typical PAMPs include lipopolysaccharides of bacteria that can be recognized by Toll-Like Receptor (TLR)4, and dsRNA of viruses that can be detected by TLR3 in endosome, retinoic acid-inducible gene I (RIG-I), and melanoma differentiation-associated gene 5 (MDA5) in the cytosol. Despite being the genetic blueprint of all life, DNA has long been known to be immune stimulatory (Isaacs et al., 1963). As a potent PAMP, DNA can be recognized by several PRRs (Table 2) (Paludan and Bowie, 2013; Unterholzner, 2013; Dempsey and Bowie, 2015; Ma et al., 2018). The first described DNA sensor that detects endosomal CpG-rich DNA to initiate type I 
TABLE 1 | Classification of human herpesviruses.

\begin{tabular}{|c|c|c|c|c|c|c|}
\hline Subfamily & Type & Synonym & Cytopathology & Primary target cells & Site of latency & Pathophysiology \\
\hline \multirow[t]{3}{*}{$\begin{array}{l}\alpha- \\
\text { herpesvirus }\end{array}$} & $\begin{array}{l}\mathrm{HHV}- \\
1\end{array}$ & $\begin{array}{l}\text { Herpes simplex virus-1 } \\
(\mathrm{HSV}-1)\end{array}$ & Cytolytic & Mucoepithelial & Neurons & Orofacial infections, Encephalitis \\
\hline & $\begin{array}{l}\mathrm{HHV}- \\
2\end{array}$ & $\begin{array}{l}\text { Herpes simplex virus-2 } \\
\text { (HSV-2) }\end{array}$ & & & & Genital and neonatal infections \\
\hline & $\begin{array}{l}\mathrm{HHV}- \\
3\end{array}$ & Varicella zoster virus (VZV) & & & & Chickenpox, Shingles \\
\hline \multirow[t]{3}{*}{$\begin{array}{l}\beta- \\
\text { herpesvirus }\end{array}$} & $\begin{array}{l}\mathrm{HHV}- \\
5\end{array}$ & Cytomegalovirus (CMV) & Cytomegalic & $\begin{array}{l}\text { Monocytes, } \\
\text { lymphocytes, epithelial } \\
\text { cells }\end{array}$ & $\begin{array}{l}\text { Macrophages, } \\
\text { lymphocytes, epithelial } \\
\text { cells }\end{array}$ & $\begin{array}{l}\text { Congenital infection, Sensorineural hearing } \\
\text { loss in children, Retinitis, Hepatitis }\end{array}$ \\
\hline & $\begin{array}{l}\mathrm{HHV}- \\
6\end{array}$ & Roseolovirus & Lymphotropic & T cells & $\begin{array}{l}\text { Monocytes/ } \\
\text { macrophages }\end{array}$ & Exanthem subitum \\
\hline & $\begin{array}{l}\mathrm{HHV}- \\
7\end{array}$ & Roseolovirus & & T cells & $\mathrm{T}$ cells & Roseola infantum \\
\hline \multirow[t]{2}{*}{$\begin{array}{l}\gamma- \\
\text { herpesvirus }\end{array}$} & $\begin{array}{l}\mathrm{HHV}- \\
4\end{array}$ & Epstein-Barr virus (EBV) & Lymphoproliferative & $\begin{array}{l}\text { B cells and epithelial } \\
\text { cells }\end{array}$ & B cells & $\begin{array}{l}\text { Infectious mononucleosis, lymphoma, } \\
\text { carcinoma }\end{array}$ \\
\hline & $\begin{array}{l}\mathrm{HHV}- \\
8\end{array}$ & $\begin{array}{l}\text { Kaposi's sarcoma- } \\
\text { associated herpesvirus } \\
\text { (KSHV) }\end{array}$ & & $\begin{array}{l}\text { Lymphocytes and } \\
\text { endothelial cells }\end{array}$ & Lymphocytes & $\begin{array}{l}\text { Kaposi's sarcoma, Primary effusion } \\
\text { lymphoma, Multicentric Castleman } \\
\text { disease }\end{array}$ \\
\hline
\end{tabular}

TABLE 2 | Characterization of the DNA sensing pathways.

\begin{tabular}{|c|c|c|c|c|c|}
\hline $\begin{array}{l}\text { Proposed DNA } \\
\text { sensor }\end{array}$ & Ligand & $\begin{array}{l}\text { Cite of } \\
\text { DNA } \\
\text { sensing }\end{array}$ & Mechanism & $\begin{array}{l}\text { Biological } \\
\text { Response }\end{array}$ & References \\
\hline TLR9 & $\begin{array}{l}\mathrm{CpG} \\
\mathrm{DNA}\end{array}$ & Endosomes & $\begin{array}{l}\text { Recognizes unmethylated CpG DNA and recruits the adaptor protein } \\
\text { MyD88 to induce activation of NF-kB and IRF7 }\end{array}$ & Type I IFN & Kawai and Akira, 2011 \\
\hline \multicolumn{6}{|l|}{ PYHIN Family } \\
\hline AlM2 & $\begin{array}{l}\text { Cytosolic } \\
\text { dsDNA }\end{array}$ & Cytoplasm & $\begin{array}{l}\text { Binds to DNA via AIM2 HIN200 domain and recruits ASC via a pyrin:pyrin } \\
\text { homotypic interaction followed by subsequent caspase activation }\end{array}$ & $\begin{array}{l}\mathrm{IL}-1 \beta \text { and } \\
\mathrm{IL}-18\end{array}$ & Hornung et al., 2009 \\
\hline \multicolumn{6}{|c|}{ Nucleotidyl Transferase Family } \\
\hline cGAS & $\begin{array}{l}\text { Cytosolic } \\
\text { dsDNA } \\
\text { Y-form } \\
\text { DNA } \\
\text { DNA- } \\
\text { RNA } \\
\text { hybrid }\end{array}$ & $\begin{array}{l}\text { Cytoplasm, } \\
\text { nucleus }\end{array}$ & $\begin{array}{l}\text { Binds to DNA and catalyzes the synthesis of cGAMP that activate STING } \\
\text { followed by subsequent activation of IRF3 }\end{array}$ & IFN- $\beta$ & $\begin{array}{l}\text { Ablasser et al., 2013; Gao } \\
\text { et al., 2013; Sun et al., } 2013\end{array}$ \\
\hline \multicolumn{6}{|c|}{ Protein Kinase (PK) Family } \\
\hline DNA-PK & $\begin{array}{l}\text { Cytosolic } \\
\text { dsDNA }\end{array}$ & Cytoplasm & $\begin{array}{l}\text { 1. Senses DNA and activates the STING-TBK1-IRF3 axis } \\
\text { 2. Induces STING independent DNA sensing pathway by triggering } \\
\text { HSPA8 and IRF3 phosphorylation }\end{array}$ & $\begin{array}{l}\text { IFN- } \lambda|,| \text { IFN- } \\
\beta, \mid L-6\end{array}$ & Burleigh et al., 2020 \\
\hline Ku70 & $\begin{array}{l}\text { Cytosolic } \\
\text { dsDNA }\end{array}$ & Cytoplasm & Senses DNA and induces the production of type III IFN & Type III IFN & Zhang et al., 2011 \\
\hline \multicolumn{6}{|c|}{ DExD/H-Box Helicase Family } \\
\hline $\mathrm{DHX9}$ and $\mathrm{DHX} 36$ & $\begin{array}{l}\text { CpG } \\
\text { DNA }\end{array}$ & Cytoplasm & Detect CpG DNA and activate an MyD88-dependent pathway & $\begin{array}{l}\text { TNF- } \alpha, \text { IFN- } \\
\alpha\end{array}$ & Kim et al., 2010 \\
\hline \multicolumn{6}{|c|}{ Other DNA sensors } \\
\hline DAl & $\begin{array}{l}\text { Cytosolic } \\
\text { dsDNA }\end{array}$ & Cytoplasm & Senses DNA and activates the STING-TBK1-IRF3 axis & IFN- $\beta$ & Takaoka et al., 2007 \\
\hline
\end{tabular}

interferon (IFN) response was TLR9 (Hemmi et al., 2000). Soon after, Absent In Melanoma 2 (AIM2) was found to sense cytosolic DNA and trigger inflammasome response (FernandesAlnemri et al., 2009; Hornung et al., 2009). Several other DNA sensors like IFN $\gamma$-Inducible protein 16 (IFI16), RNA polymerase III (Pol III), and the Mre11-Rad50-Nbs1 (MRN) complex, have also been reported (Goubau et al., 2013; Paludan, 2015; Volkman et al., 2019). The most recently reported DNA sensor is cyclic 
GMP-AMP Synthase (cGAS) which was discovered by Dr. Zhijian "James" Chen's group through elegant biochemical approaches (Sun et al., 2013; Wu et al., 2013). Binding to dsDNA activates cGAS, leading to generation of unique second messenger cGAMP that binds to stimulator of interferon genes (STING) and activates downstream signaling (Ablasser et al., 2013; Gao et al., 2013; Sun et al., 2013). Numerous studies have shown cGAS to be the non-redundant principal cytosolic DNA sensor in most cells. All PRRs share similar modes of action: after the recognition of PAMPs, PRRs induce intracellular signaling pathways through the hierarchical activation of a PRR familyspecific adaptor protein. This leads to the expression of genes with pro-inflammatory and microbicidal activities, including cytokines and type I IFNs. Secreted cytokines and chemokines are also critical for shaping effective adaptive immune responses (Akira et al., 2006; Brubaker et al., 2015).

To overcome host defenses, viruses, including herpesviruses, have evolved multiple strategies to evade immune recognition by PRRs (Bowie and Unterholzner, 2008; Beachboard and Horner, 2016; Chan and Gack, 2016; Lee et al., 2019). These strategies include sequestration or modification of viral nucleic acids, sequestration of PRRs, degradation or cleavage of host sensors or their adaptor proteins, interference with specific posttranslational modifications of PRRs or their adaptor proteins, and inhibition of the enzymatic activity of PRRs. Evasion of the host innate immune response is crucial for herpesviruses to persist in their hosts. Therefore, understanding immune evasion strategies will advance our knowledge of viral/host interplay and viral pathogenesis in general, and will inform the development of preventive or therapeutic strategies against herpesvirusesassociated diseases. In this review, we will discuss how human herpesviruses are sensed by the host innate immune system, with a focus on the DNA sensors, and elaborate the common evasion strategies that target different steps in this signaling pathway.

\section{DETECTION OF HERPESVIRUSES BY PRRs}

Herpesvirus virions contain a large, double-stranded DNA genome encased in a highly ordered icosahedral nucleocapsid. The nucleocapsid is coated with an amorphous layer known as tegument, consisting mostly viral proteins; which layer in turn is encased in a lipid bilayer envelope bearing distinct viral glycoproteins. Upon entry of the virus into host cells, some tegument proteins are released and the capsid is transported to the host nuclear membrane to deliver viral DNA into the nucleus. Transcription, replication of the viral genome, and assembly of the capsid take place in the nucleus (Boehmer and Nimonkar, 2003; Heming et al., 2017). The mature nucleocapsid egresses to the cytoplasm where it acquires tegument and envelope. The mature virions are transported through vesicles and finally released into the extracellular space. Alternatively, herpesviruses can maintain a latent state during which the viral genome is mostly silent and maintained as an episome in the nucleus with no progeny produced. The latent genome can be reactivated to initiate lytic replication upon certain cellular stress cues (Speck and Ganem, 2010; Cohen, 2020). The innate immune system is expected to recognize the components of the herpesvirus viral particles and replication intermediates produced during infection. Besides viral DNA, leaked mtDNA as a result of cellular stress from viral infection can also be sensed by DNA sensors such as cGAS (Paludan et al., 2011; Reinert et al., 2016; Sun et al., 2019).

\section{TLR9}

Toll-like receptors are the first characterized PRRs shown to recognize herpesviral PAMPs, including viral proteins, DNA and RNA. Among the TLRs, TLR2 detects virion components (Boehme et al., 2006; Leoni et al., 2012; Cai et al., 2013), while TLR3 and 9 recognize herpesvirus nucleic acid (Paludan et al., 2011; West et al., 2012). Specifically, TLR3 senses dsRNA (Iwakiri et al., 2009) and TLR9 detects endosomal dsDNA containing un-methylated $\mathrm{CpG}$ motifs that are commonly found in the herpesviral genome (Lund et al., 2003; Fiola et al., 2010). After DNA sensing, TLR9 recruits the adaptor protein MyD88 and induces the activation of Nuclear Factor $\kappa B(N F-\kappa B)$ and Interferon Regulatory Factor (IRF)7, leading to the production of IFN- $\alpha$ in plasmacytoid Dendritic Cells (pDCs) (Kawai and Akira, 2011) (Figure 1). Infections from HSV-1, HSV-2, KSHV, and EBV have been shown to stimulate TLR9mediated production of type I IFN in pDCs (Lund et al., 2003; Krug et al., 2004; Fiola et al., 2010; West et al., 2011; Ma and He, 2014). Infection from HSV-2 also induces a TLR9-mediated type III IFN response in DCs that relies more on NF- $\kappa B$ rather than IRFs (Iversen et al., 2010). HSV-induced activation of TLR9mediated innate immune response is apparently cell-typespecific (Rasmussen et al., 2007). Krug et al. have shown that knockout of TLR9 causes no dramatic enhancement of HSV infection in mice (Krug et al., 2004), whereas another study reported that TLR9 expression in the trigeminal ganglia was required to prevent $\mathrm{HSV}$ encephalitis induced by intranasal HSV-1 infection, as TLR9 deficient mice were more susceptible to the virus, with $60 \%$ mortality (Lima et al., 2010).

\section{cGAS}

The cyclic GMP-AMP synthase (cGAS) is the most recently discovered DNA sensor (Sun et al., 2013). It senses doublestranded DNA in a length-dependent but sequence-independent manner (Andreeva et al., 2017; Luecke et al., 2017). Binding to dsDNA leads to the formation of phase-separated liquid droplets in which cGAS is activated, and catalyzes the synthesis of cyclic GMP-AMP (cGAMP) from ATP and GTP (Du and Chen, 2018). As a second messenger, cGAMP activates ER-bound adaptor protein STING (STimulator of Interferon Genes) in the same cells or neighboring cells. Activated STING recruits kinase TBK1 and activates transcriptional factor IRF3 to initiate a downstream signaling cascade that culminates the expression of immune and inflammatory genes, such as type I IFNs (Tanaka and Chen, 2012) (Figure 1). Previously, it was thought that the cytoplasmic confinement of cGAS enabled it to specifically 


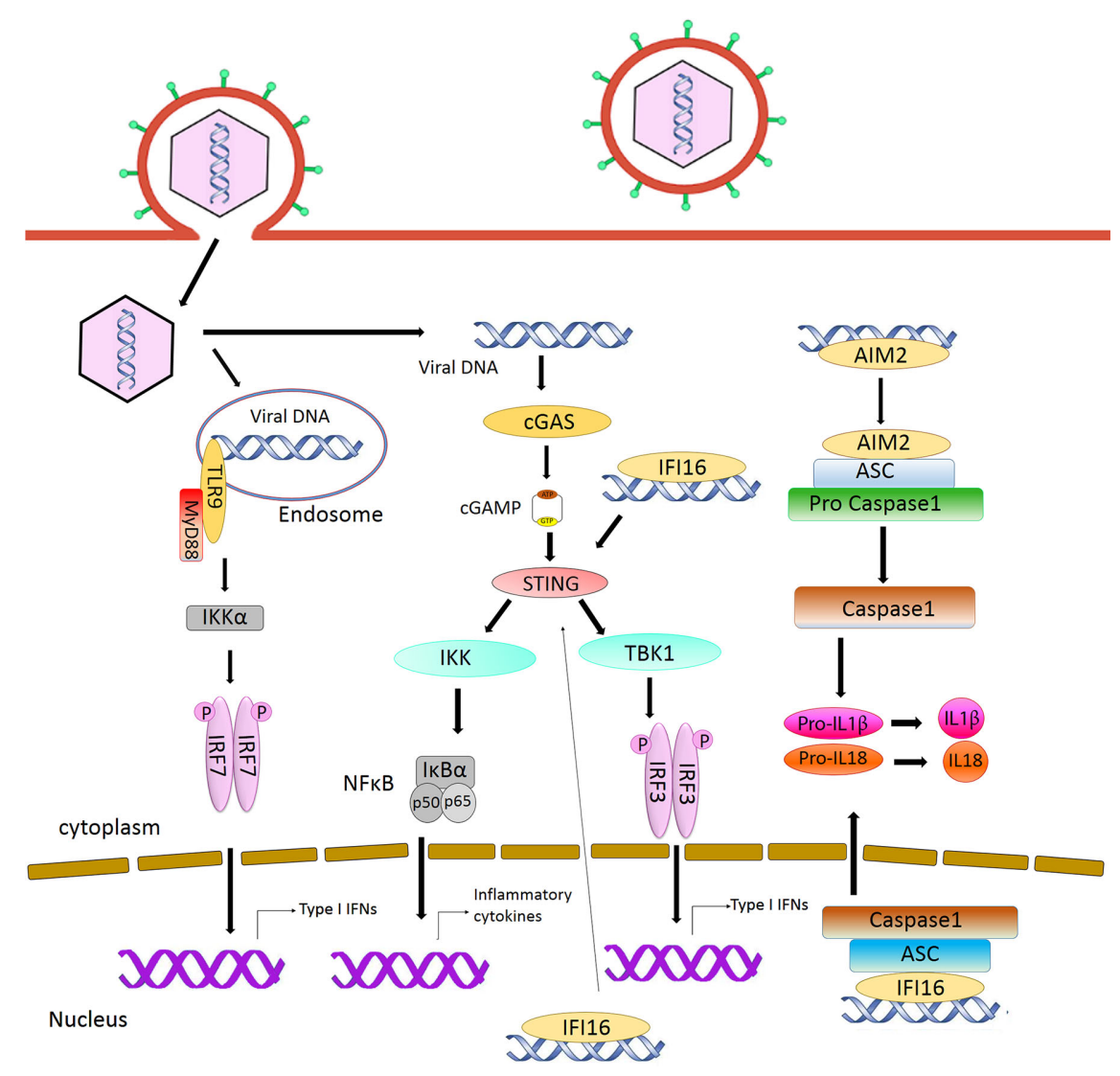

FIGURE 1 | Intracellular sensing of herpesvirus DNA by DNA sensors and activation of signaling pathway. CpG DNA in the endosome is sensed by TLR9, leading to the production of type I interferon. AIM2 and IFI16 detect DNA in the cytoplasm and nucleus respectively and activate inflammasome pathway. Detection of DNA by cGAS activates STING signaling, resulting in the induction of type I interferon.

recognize pathogen- or damage-associated DNA. However, recent works revealed that cGAS is predominantly nuclear and its tight tethering to the chromatin is important in preventing its auto-reactivity (Volkman et al., 2019; Zierhut et al., 2019; Boyer et al., 2020; Kujirai et al., 2020; Michalski et al., 2020; Pathare et al., 2020; Zhao et al., 2020). The cGAS-cGAMP-STING pathway is crucial for host response to herpesviral infection. Sensing of HSV-1 DNA by microglia in the brain, and in PMAdifferentiated macrophage-like THP1, induces type I IFN in a cGAS-STING dependent manner (Reinert et al., 2016), and cGAS deficient mice were found to be more susceptible to HSV-1 infection (Li X. D. et al., 2013; Christensen et al., 2016). Infection with HCMV was reported to activate the cGAS-STING pathway in primary Human Umbilical Vein Endothelial Cells (HUVEC) and in monocytic leukemia cell line THP-1 (Lio et al., 2016; Paijo et al., 2016). Although it has been reported that KSHV infection is also sensed by the cGAS-STING pathway and this pathway regulates the reactivation of KSHV from latency (Ma et al., 2015; Zhang et al., 2016), a recent report has shown that STING signaling is not critical in KSHV latent infection, replication, or in its spread after lytic reactivation in endothelial cells (Vogt et al., 2020).
AIM2

Absent in melanoma 2 (AIM2) is a cytosolic DNA sensor that belongs to the PYHIN protein family. It contains an N-terminal Pyrin domain and one C-terminal HIN domain. The HIN domain binds to DNA through electrostatic interaction and the Pyrin domain associates with the adaptor protein ASC (apoptosis-associated speck-like protein containing a caspase activation and recruitment domain) through a homotypic PYRIN : PYRIN interaction. ASC further recruits pro caspase-1, leading to the production of active caspase-1. Caspase-1 in turn causes proteolytic maturation of the proinflammatory cytokines interleukin IL1 $\beta$ and IL18 (Hornung et al., 2009) (Figure 1). It has been shown that HCMV triggers the assembly of AIM2 inflammasome in THP-1-derived macrophages (Huang et al., 2017a; Botto et al., 2019). HSV-1 also induces AIM2dependent inflammasome activation and IL-1 $\beta$ secretion in the absence of tegument protein VP22 in macrophages (Maruzuru et al., 2018).

\section{IFI16}

Another member of the PYHIN family, IFI16, recognizes double-stranded DNA both in the cytosol and in the nucleus 
(Unterholzner et al., 2010). It contains an N-terminal Pyrin domain and two HIN domains in the C-terminus. The interaction with DNA takes place through the HIN domains. Similar to cGAS and AIM2, IFI16 also recognizes DNA in a length-dependent manner (Stratmann et al., 2015). IFI16 primarily localizes in the nucleus, where the DNA genome of large DNA virus resides and replicates. Kerur et al. showed for the first time that IFI16 acts as a nuclear DNA sensor of herpesvirus infection. Nuclear sensing of KSHV and EBV by IFI16 results in inflammasome responses through ASC and caspase-1, leading to the production of IL1 $\beta$ and IL18 (Kerur et al., 2011; Ansari et al., 2013; Johnson et al., 2013). IFI16 appears to interfere with HSV-1 replication. It has been shown that IFI16 binds to the HSV-1 genome at the transcription start sites of several viral genes, and blocks the recruitment of crucial cellular transcription factors to the promoters (Johnson et al., 2014). IFI16 was also found to be crucial for the maintenance of EBV latency (Pisano et al., 2017). It has been reported that IFI16 forms filamentous structure on DNA in the nucleus to promote the epigenetic silencing of viral DNA (Merkl and Knipe, 2019; Roy et al., 2019). Although IFI16 is predominantly nuclear, it can also detect DNA in the cytosol. During HSV-1 infection, IFI16 has been found to co-localize with viral genomic DNA in the cytoplasm. It is also probable that IFI16 binds to the viral genome in the nucleus and interacts with histone acetyltransferase p300. Acetylation of IFI16 results in its cytoplasmic redistribution, where it interacts with STING and subsequently induces IRF-3 phosphorylation as well as interferon- $\beta$ production (Ansari et al., 2015). The stability of IFI16 is enhanced in the presence of the principal DNA sensor cGAS, and depletion of cGAS results in reduced expression of IL-6 transcript in a STING-independent manner (Orzalli et al., 2015). Recent studies have shown that IFI16 and cGAS both function cooperatively for the full activation of innate immune response to exogenous DNA (Orzalli et al., 2015; Almine et al., 2017; Jønsson et al., 2017).

\section{Other DNA Sensors}

The first reported cytosolic DNA sensor was DNA-dependent activator of IRFs (DAI) (Takaoka et al., 2007). It detects DNA in the cytosol and activates type I IFNs through NF- $\mathrm{KB}$ and IRF3. Type I interferon expression in HCMV-infected fibroblast cells was reported to depend on DAI (Defilippis et al., 2010), which was shown to interact with receptor-interacting protein kinase (RIP)3 to arbitrate virus-induced necrosis during $\mathrm{MCHV}$ infection (Upton et al., 2012). DExD/H-box helicases DHX36 and DHX9 are the two sensors that detect CpG DNA and activate an MyD88-dependent pathway in pDCs (Kim et al., 2010). However, the interferon response and inflammatory response only partially depend on DHX36 and DHX9 respectively, presumably because TLR9 is the main sensor for CpG DNA. Several proteins involved in DNA damage repair can also serve as DNA sensors (Mboko et al., 2012). Meiotic recombination 11 homolog $\mathrm{A}$ (MRE11) and DNA-dependent protein kinase (DNA-PK) belong to that group. MRE11 also recognizes dsDNA and induces type I interferon (Kondo et al., 2013). DNA-PK is a heterotrimeric protein complex consisting of three subunits: Ku70, Ku80, and the catalytic subunit DNA-
PKcs (Ferguson et al., 2012). It can exert antiviral responses in a STING-dependent and a STING-independent manner (Burleigh et al., 2020). The protein was shown to act as a DNA sensor and mediate the induction of type III interferon (Zhang et al., 2011). During HSV infection, cytokine response is impaired both in mice and in individual cells that are deficient in DNA-PK (Ferguson et al., 2012). Interestingly, DNA-PKcs activity has been previously reported to be degraded in an Infected Cell Protein 0 (ICP0) dependent manner in some cell types during HSV infection (Lees-Miller et al., 1996; Parkinson et al., 1999). The role of DNA-PK in sensing other herpesviruses is less clear, although EBV has been shown to trigger a DNA damage response (DDR) during both primary infection and lytic reactivation (Hafez and Luftig, 2017; Hau and Tsao, 2017). It has been recently shown that DNA damage results in the translocation of the principal DNA sensor cGAS to the nucleus, where it suppresses DNA repair and enhances cell proliferation. Thus cGAS appears to exhibit dual functions: as an innate immune sensor in the cytosol and as a negative regulator of DNA repair in the nucleus (Liu et al., 2018; Jiang et al., 2019).

\section{EVASION OF DNA-STIMULATED IMMUNE RESPONSES BY HERPESVIRUSES}

The DNA genome of herpesvirus is shielded within the viral capsid until it reaches the nucleus. The nuclear DNA sensors IFI16 and hnRNP-A2B1 may recognize the viral DNA in the nucleus and translocate to the cytoplasm to elicit the immune response (Diner et al., 2015; Knipe, 2015; Wang et al., 2019). On the other hand, a defective virion could leak DNA into the cytoplasm that could be sensed by the cytosolic DNA sensors. This second notion is supported by observations that mutations altering capsid stability result in leakage of viral DNA in the cytoplasm and robust DNA sensing responses (Horan et al., 2013; Sun et al., 2019). Herpesvirus infection also induces mtDNA stress, which triggers antiviral responses (West et al., 2015). In order to persist in the hosts, viruses must overcome host immune defenses. Herpesviruses have evolved delicate strategies to avoid the host immune recognition. Here we will discuss evasion strategies (Table 3) that target either DNA sensors or their adaptor proteins to counteract the nuclear and cytoplasmic DNA sensing.

\section{Direct Inhibition of the Enzymatic Activity of the DNA Sensor}

Viruses encode factors that can directly target the host DNA sensors to block their activation. Unique among the known DNA sensors, cGAS has catalytic activity and transmits signal through its enzymatic product cGAMP. Conceivably, interfering with the production of cGAMP or destroying cGAMP could be effective viral evasion strategies. While poxviruses and baculoviruses encode Poxin, a nuclease that degrades cGAMP, herpesviruses encode factors that directly inhibit cGAS activity. KSHV tegument protein ORF52 (KicGAS) was the first discovered 
TABLE 3 | Herpesvirus proteins that regulate DNA sensing and DNA activated signaling pathway.

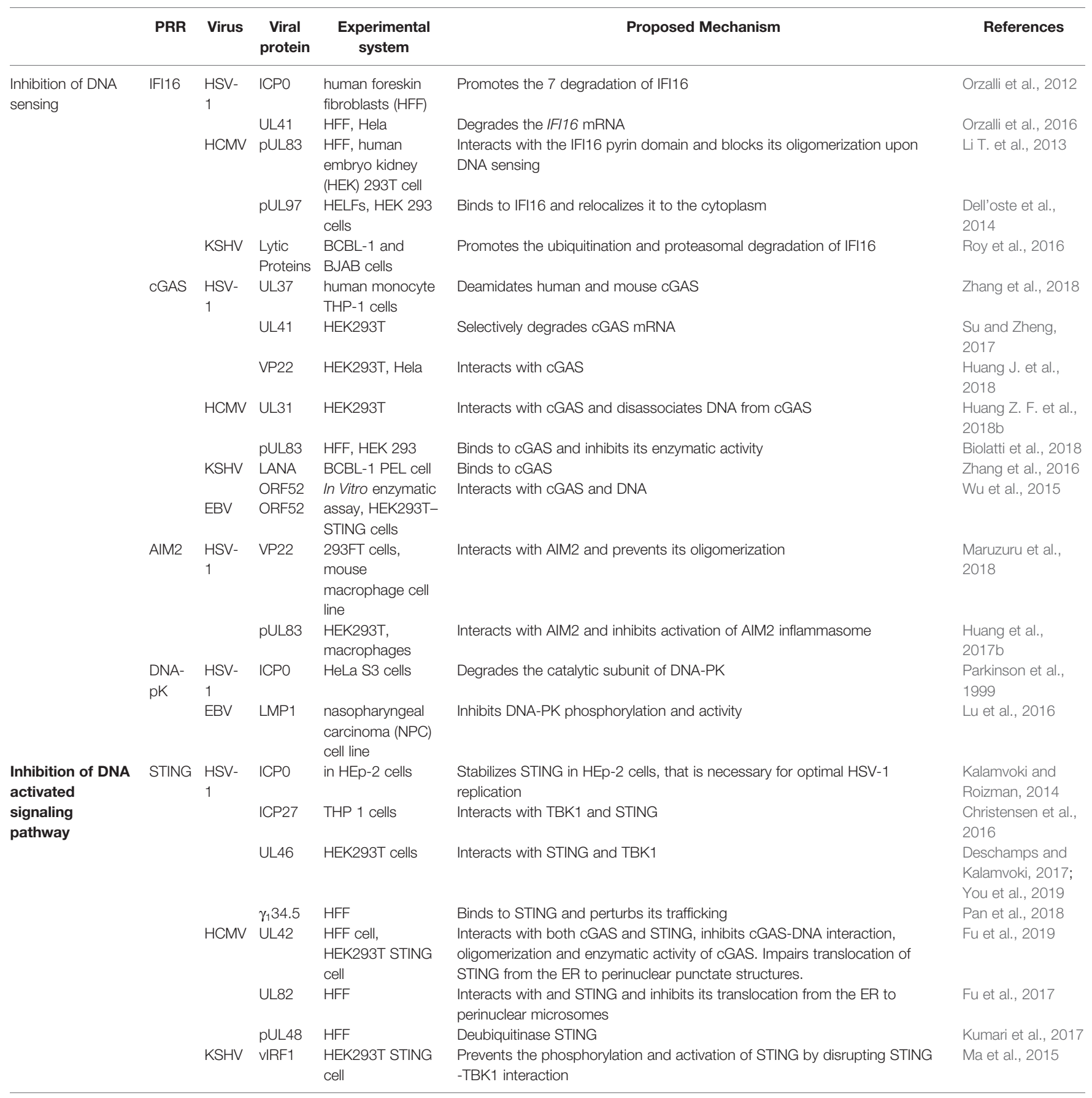

inhibitor of cGAS enzymatic activity. KicGAS is a positively charged small and abundant tegument protein that binds to DNA efficiently. Purified KicGAS protein was shown to inhibit cGAS activity in a dose-dependent manner. This inhibition depends on its ability to bind DNA and cGAS. The inhibition of cGAS by KicGAS can be partially overcome by increasing the amount of DNA in the reaction, suggesting KicGAS uses a mechanism involving competition with DNA (Wu et al., 2015). In addition to KicGAS homologues in gamma herpesviruses, HSV-1 VP22, which exhibits limited structural homology to
KicGAS, has also been reported to inhibit cGAS. Although no in vitro experimental data were shown, we suspect similar mechanisms were involved (Hew et al., 2015; Huang J. et al., 2018). Cytoplasmic isoforms of KSHV LANA (latencyassociated nuclear antigen) interact with cGAS directly and block downstream signaling (Zhang et al., 2016). Two HCMV proteins, UL31 and UL42, interact with cGAS and interfere with cGAS-DNA binding (Figure 2) (Huang Z. F. et al., 2018; $\mathrm{Fu}$ et al., 2019). Another HCMV tegument protein, pUL83, selectively binds to cGAS and inhibits its enzymatic activity. 


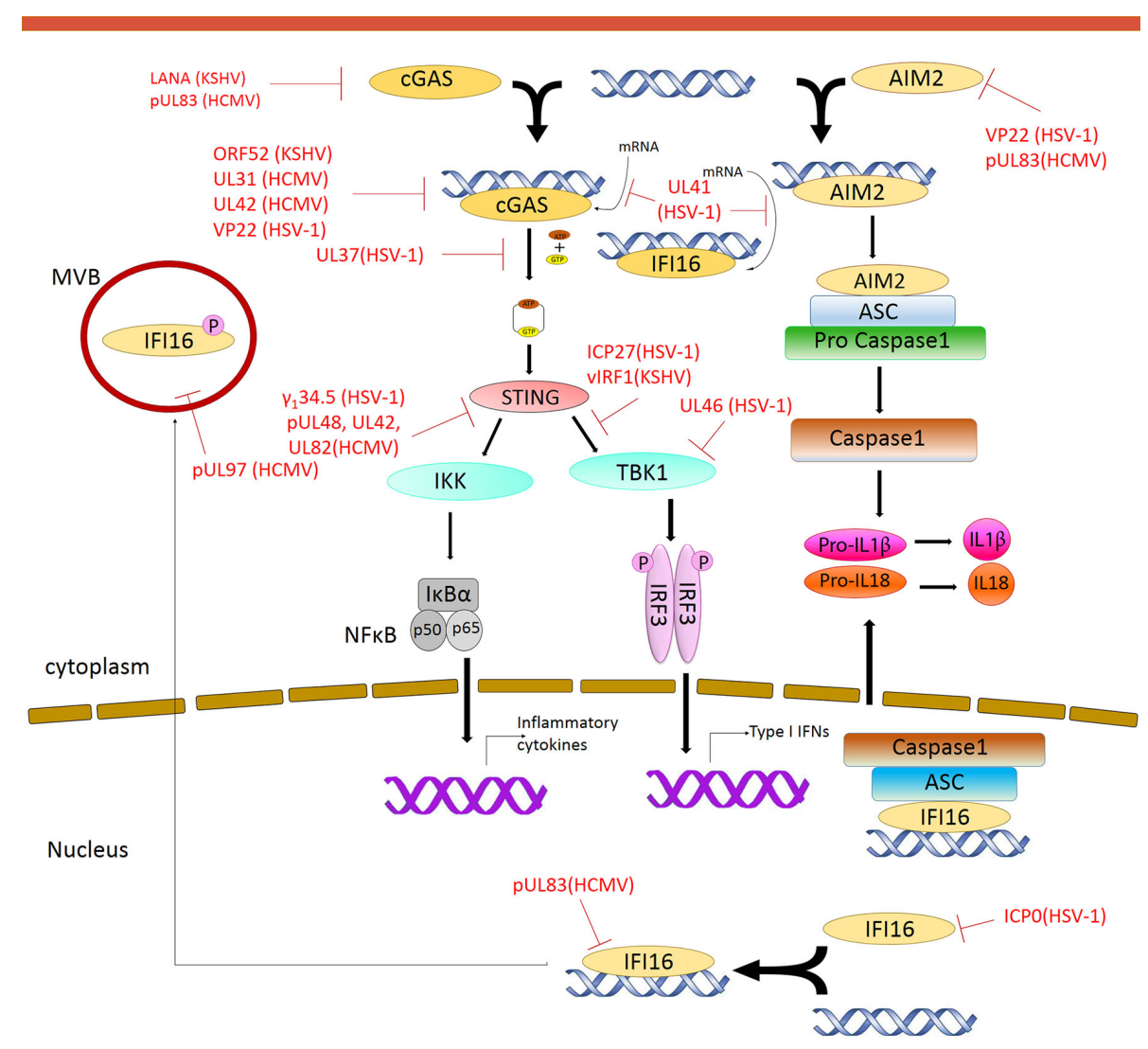

FIGURE 2 | Modulation of DNA Sensing pathways by herpesvirus. Multiple steps in the signaling pathway are targeted by herpesvirus encoded proteins. Red solid line indicates inhibition of a particular pathway by the respective herpesvirus protein.

The N-terminal domain of pUL83 appears to play an important role in binding, and the interaction is independent of viral DNA (Biolatti et al., 2018).

\section{Masking of the DNA Sensors}

Another strategy used by the herpesvirus is to mask the DNA sensor to prevent downstream signaling. The DNA sensors that were shown to be sequestered by herpesviral proteins are IFI16 and AIM2. In addition to inhibit the enzymatic activity of cGAS, HSV-1 VP22 was also shown to interact with AIM2; the association is mediated by the HIN domain of AIM2. This interaction prevents the oligomerization of AIM2 (Maruzuru et al., 2018), which is the first step of AIM2-dependent inflammasome activation. The HCMV abundant virion protein pUL83 interacts with AIM2 and IFI16 in the cytoplasm and nucleus respectively (Figure 2) (Li T et al., 2013; Huang et al., 2017b). Interaction between pUL83 and AIM2 reduces the expression of inflammosome proteins and decreases the cleavage of caspase- 1 and maturation of IL-1 $\beta$. The protein pUL83 contains an N-terminal conserved pyrin association domain (PAD) that interacts with the Pyrin domain of IFI16. It inhibits the nuclear oligomerization of IFI16 by sequestering the pyrin domain through the combined action of its conserved
$\mathrm{N}$ - and C-terminals. Such oligomerization is essential for IFI16mediated DNA-dependent immune signaling.

\section{Degradation of the DNA Sensors}

In order to prevent activation of the DNA sensors, herpesviral proteins may target them for degradation. The DNA sensors IFI16, DNA-PK, RNF8, and RNF168 were shown to be degraded during herpesvirus infection. The ring finger domain of HSV-1 ICP0 exhibits E3 ubiquitin ligase activity. The nuclear form of the ICP0 protein was shown to interact with IFI16, relocalize IFI16 to ICP0-containing foci in the nucleus, and promote the proteasomal degradation of IFI16, resulting in impaired sensing of HSV-1 genome in HFFs (Orzalli et al., 2012; Johnson et al., 2013) (Figure 2). However, another study showed that ICP0 was neither required nor sufficient to promote the loss of IFI16 in U2OS and HepaRG cells (Cuchet-Lourenço et al., 2013), suggesting that the ICP0-mediated degradation of IFI16 could be cell-type specific. Studies also found IFI16 to be degraded during KSHV lytic replication, likely through the action of late protein(s) (Roy et al., 2016). ICP0 was reported to promote the proteasomal degradation of DNA-PK, RNF8, and RNF168, and modulate the DDR response (Parkinson et al., 1999; 
Lilley et al., 2011). The two ubiquitin ligases that anchor the repair factors at sites of damage (Parkinson et al., 1999; Chaurushiya et al., 2012).

In addition, viral proteins can also promote the selective degradation of host mRNA and reduce the level of the DNA sensors cGAS and IFI16. The HSV-1 tegument protein UL41 was shown to selectively degrade cGAS mRNA via its mRNA-specific RNase activity, reduce the level of cGAS, and downregulate cGAS STING-mediated signaling (Su and Zheng, 2017). UL41 was also reported to contribute to the reduction of IFI16 levels (Orzalli et al., 2016).

\section{Post-Translational Modification of the DNA Sensors}

DNA sensing is also regulated by post-translational modifications including phosphorylation, ubiquitination, acetylation, sumoylation, and glutamylation of the DNA sensors (Wu and Li, 2020). Acetylation and phosphorylation of IFI16 at different sites have been shown to regulate its subcellular localization (Li et al., 2012). HCMV viral protein kinase pUL97 phosphorylates IFI16 and triggers its relocalization from nucleus to cytoplasm, away from the HCMV genome in the nucleus, thus inhibiting nuclear sensing of viral DNA (Dell'oste et al., 2014). However, ectopic expression of pUL97 alone was insufficient to relocate IFI16, suggesting additional HCMV components may be involved. HSV-1 tegument protein UL37 deamidates a critical Asp in the activation loop of human and mouse cGAS, resulting in impaired cGAMP synthesis (Zhang et al., 2018) (Figure 2). It was previously demonstrated that DNA binding leads to conformation change in the activation loop of cGAS that is required for its catalytic activity (Zhang et al., 2014). The deamination of Asp in the activation loop presumably blocks the conformational change. It is to be noted that this Asp is not conserved in non-human primates, thus HSV-1 mediates species specific inactivation of cGAS.

\section{Interfering With the Downstream Signaling Pathway}

Most DNA sensors transmit signals through the adaptor protein STING, which possesses both interferon-dependent and interferon-independent immune responses (Wu et al., 2020; Yamashiro et al., 2020). After activation, STING translocates from the ER to endosomal/lysosomal perinuclear regions where it associates with the kinase TBK1 (Ishikawa and Barber, 2008). This interaction mediates the activation of transcription factors IRF3 and (NF- $\mathrm{KB})$, and promotes the expression of immune and inflammatory genes, such as type I IFNs (Tanaka and Chen, 2012). In order to antagonize the STING-mediated immune response, herpesvirus encodes a number of proteins that directly target STING for deubiquitination, perturb its intracellular trafficking, or block its interaction with other signaling partners (Ahn and Barber, 2019; Liu et al., 2019; Yang et al., 2019). HSV-1 protein pUL36 directly associates with and deubiquitinate STING and perturbs its downstream signaling (Bodda et al., 2020). HCMV protein pUL48 was also reported to deubiquitinate STING (Kumari et al., 2017). The HSV-1 protein $\gamma_{1} 34.5$, and HCMV tegument proteins UL42 and
UL82, were shown to impair STING trafficking from the ER to the Golgi apparatus. Protein UL82 interacts with STING and ERassociated protein iRhom2, and disrupts the iRhom2-mediated formation of the STING-TRAP $\beta$ translocon complex (Fu et al., 2017). On the other hand, UL42 does not interact with iRhom2. It promotes the degradation of TRAP $\beta$ and inhibit STING trafficking (Fu et al., 2019). But how HSV-1 $\gamma_{1} 34.5$ blocks STING signaling is not clearly understood (Pan et al., 2018). The proteins vIRF1 of KSHV and ICP27 and UL46 of HSV-1, were shown to disrupt STING-TBK1 interaction. Interaction between vIRF1 and STING inhibits the STING-mediated phosphorylation of TBK1 (Ma et al., 2015). But ICP27 interacts with the STING-TBK1 signalosome and inhibits the phosphorylation of IRF3 by TBK1 (Christensen et al., 2016). In addition, UL46 interacts with STING and TBK1 via its N- and Ctermini respectively and impairs the activation of IRF3 by inhibiting the dimerization of TBK1 (Deschamps and Kalamvoki, 2017; You et al., 2019). Interestingly, ICP0 of HSV-1 was found to stabilize STING in certain cell types such as HEp-2 cells, as it is needed for optimal HSV-1 infection in those cells (Kalamvoki and Roizman, 2014). In addition, herpesviral proteins also target STING interaction partners to attenuate innate immune response downstream of STING (Christensen and Paludan, 2017; Liu et al., 2019). Thus, herpesvirus evolved mechanisms targeting various steps of DNA sensing to block immune response.

\section{CONCLUSION AND PERSPECTIVES}

With the discovery of a number of DNA sensors over the past decade, significant progress has been made on understanding the host innate immune response to herpesviruses. Along with this, our understanding on how herpesviruses target different steps of this signaling pathway to establish persistent infection has greatly expanded. However, there are still several key questions that need to be answered. First, if most of the DNA sensors recognize DNA in sequence independent manner, then what is the need of so many DNA sensing pathways, and what are their relative contributions to in vivo DNA sensing? One possibility is that the presence of multiple DNA sensing pathways in different cellular compartments may provide multiple opportunities for the innate immune recognition of aberrant DNA (Emming and Schroder, 2019). Different DNA sensors may require different ligand (DNA concentration) thresholds for their activation. So, it may be helpful for the cell to fine-tune the immune response based on the escalating level of danger imposed by viral infection. It remains a major challenge to understand how these pathways act in concert to detect and elicit cell-type-specific or species-specific responses to DNA. Second, nuclear sensors are hypothesized to bind to unchromatinized viral DNA to initiate innate signaling, but viral DNA is chromatinized upon entry into the nucleus. Therefore, the process of nuclear DNA sensing and the time frame between entry and the chromatinizaton of viral DNA is crucial and needs further investigation. Future efforts are necessary to better 
understand how nuclear-originating immune signaling is transmitted to the cytosol and back to the nucleus. Recently it has been shown that the dsDNA sensor heterogeneous nuclear ribonucleoprotein $\mathrm{A} 2 \mathrm{~B} 1$ (hnRNP-A2B1) recognizes viral dsDNA in the nucleus, then dimerizes and translocates to the cytosol to initiate type 1 interferon response via TBK1-IRF3 pathway (Wang et al., 2019). Further studies on the molecular mechanism by which the host nuclear DNA sensors such as hnRNP-A2B1 discriminate viral DNA from self genomic DNA will be critical for understanding nuclear DNA sensing. Third, a number of immune evasion strategies have been discovered recently, but the detailed mechanisms remain to be elucidated in most cases. Better understanding of the viral immune evasion mechanisms should aid in the development of vaccines and antivirals against herpesviruses.

In addition, herpesviruses can cause long-lasting infection as a result of the mutualistic equilibrium between the ability of the virus to survive under host antiviral immunity and the ability of the host to tolerate the presence of the virus continuously (CruzMuñoz and Fuentes-Pananá, 2018). The mutualistic equilibrium is not always beneficial to the host. It may lead to disease characterized by the abnormality in the immune system. Moreover, there is a significant overlap between the PRRs that

\section{REFERENCES}

Ablasser, A., Goldeck, M., Cavlar, T., Deimling, T., Witte, G., Röhl, I., et al. (2013). cGAS produces a 2'-5'-linked cyclic dinucleotide second messenger that activates STING. Nature 498, 380-384. doi: 10.1038/nature12306

Ahn, J., and Barber, G. N. (2019). STING signaling and host defense against microbial infection. Exp. Mol. Med. 51, 1-10. doi: 10.1038/s12276-019-0333-0

Akira, S., Uematsu, S., and Takeuchi, O. (2006). Pathogen recognition and innate immunity. Cell 124, 783-801. doi: 10.1016/j.cell.2006.02.015

Almine, J. F., O’hare, C., Dunphy, G., Haga, I. R., Naik, R. J., Atrih, A., et al. (2017). IFI16 and cGAS cooperate in the activation of STING during DNA sensing in human keratinocytes. Nat. Commun. 8, 14392-14392. doi: 10.1038/ ncomms14392

Andreeva, L., Hiller, B., Kostrewa, D., Lässig, C., De Oliveira Mann, C. C., Jan Drexler, D., et al. (2017). cGAS senses long and HMGB/TFAM-bound U-turn DNA by forming protein-DNA ladders. Nature 549, 394-398. doi: 10.1038/nature23890

Ansari, M. A., Singh, V. V., Dutta, S., Veettil, M. V., Dutta, D., Chikoti, L., et al. (2013). Constitutive interferon-inducible protein 16-inflammasome activation during Epstein-Barr virus latency I, II, and III in B and epithelial cells. J. Virol. 87, 8606-8623. doi: 10.1128/JVI.00805-13

Ansari, M. A., Dutta, S., Veettil, M. V., Dutta, D., Iqbal, J., Kumar, B., et al. (2015). Herpesvirus Genome Recognition Induced Acetylation of Nuclear IFI16 Is Essential for Its Cytoplasmic Translocation, Inflammasome and IFN- $\beta$ Responses. PloS Pathog. 11, e1005019. doi: 10.1371/journal.ppat.1005019

Beachboard, D. C., and Horner, S. M. (2016). Innate immune evasion strategies of DNA and RNA viruses. Curr. Opin. Microbiol. 32, 113-119. doi: 10.1016/ j.mib.2016.05.015

Biolatti, M., Dell'oste, V., Pautasso, S., Gugliesi, F., Von Einem, J., Krapp, C., et al. (2018). Human Cytomegalovirus Tegument Protein pp65 (pUL83) Dampens Type I Interferon Production by Inactivating the DNA Sensor cGAS without Affecting STING. J. Virol. 92, e01774-17. doi: 10.1128/JVI.01774-17

Bodda, C., Reinert, L. S., Fruhwürth, S., Richardo, T., Sun, C., Zhang, B.C., et al. (2020). HSV1 VP1-2 deubiquitinates STING to block type I interferon expression and promote brain infection. J. Exp. Med. 217, e20191422(1-15).

Boehme, K. W., Guerrero, M., and Compton, T. (2006). Human cytomegalovirus envelope glycoproteins $\mathrm{B}$ and $\mathrm{H}$ are necessary for TLR2 activation in permissive cells. J. Immunol. 177, 7094-7102. doi: 10.4049/jimmunol.177.10.7094 sense herpesvirus and the PRRs involved in autoimmune disease. Further investigation in this area is necessary to identify the missing link between herpesvirus and autoimmune disease that could be useful to reduce unwanted inflammation.

\section{AUTHOR CONTRIBUTIONS}

$\mathrm{DB}$ and FZ wrote the manuscript and designed the figures. All authors contributed to the article and approved the submitted version.

\section{FUNDING}

This work is funded by NIH grants R01 DE026101 to FZ.

\section{ACKNOWLEDGMENTS}

We also thank Jen Kennedy and Alexis Davis at The Florida State University for editorial assistance.

Boehmer, P. E., and Nimonkar, A. V. (2003). Herpes virus replication. IUBMB Life $55,13-22$.

Botto, S., Abraham, J., Mizuno, N., Pryke, K., Gall, B., Landais, I., et al. (2019). Human Cytomegalovirus Immediate Early $86-\mathrm{kDa}$ Protein Blocks Transcription and Induces Degradation of the Immature Interleukin-1 $\beta$ Protein during Virion-Mediated Activation of the AIM2 Inflammasome. mBio 10, e02510-e02518. doi: 10.1128/mBio.02510-18

Bowie, A. G., and Unterholzner, L. (2008). Viral evasion and subversion of pattern-recognition receptor signalling. Nat. Rev. Immunol. 8, 911-922. doi: $10.1038 /$ nri2436

Boyer, J. A., Spangler, C. J., Strauss, J. D., Cesmat, A. P., Liu, P., Mcginty, R. K., et al. (2020). Structural basis of nucleosome-dependent cGAS inhibition. Science, 370, 450-454. doi: 10.1126/science.abd0609

Brubaker, S. W., Bonham, K. S., Zanoni, I., and Kagan, J. C. (2015). Innate immune pattern recognition: a cell biological perspective. Annu. Rev. Immunol. 33, 257-290. doi: 10.1146/annurev-immunol-032414-112240

Burleigh, K., Maltbaek, J. H., Cambier, S., Green, R., Gale, M., James, R. C., et al. (2020). Human DNA-PK activates a STING-independent DNA sensing pathway. Sci. Immunol. 5, eaba4219. doi: 10.1126/sciimmunol.aba4219

Cai, M., Li, M., Wang, K., Wang, S., Lu, Q., Yan, J., et al. (2013). The herpes simplex virus 1-encoded envelope glycoprotein $\mathrm{B}$ activates NF- $\mathrm{KB}$ through the Toll-like receptor 2 and MyD88/TRAF6-dependent signaling pathway. PloS One 8, e54586. doi: 10.1371/journal.pone.0054586

Chan, Y. K., and Gack, M. U. (2016). Viral evasion of intracellular DNA and RNA sensing. Nat. Rev. Microbiol. 14, 360-373. doi: 10.1038/nrmicro.2016.45

Chaurushiya, M. S., Lilley, C. E., Aslanian, A., Meisenhelder, J., Scott, D. C., Landry, S., et al. (2012). Viral E3 ubiquitin ligase-mediated degradation of a cellular E3: viral mimicry of a cellular phosphorylation mark targets the RNF8 FHA domain. Mol. Cell 46, 79-90. doi: 10.1016/j.molcel.2012.02.004

Christensen, M. H., and Paludan, S. R. (2017). Viral evasion of DNA-stimulated innate immune responses. Cell. Mol. Immunol. 14, 4-13. doi: 10.1038/cmi.2016.06

Christensen, M. H., Jensen, S. B., Miettinen, J. J., Luecke, S., Prabakaran, T., Reinert, L. S., et al. (2016). HSV-1 ICP27 targets the TBK1-activated STING signalsome to inhibit virus-induced type I IFN expression. EMBO J. 35, 13851399. doi: $10.15252 / \mathrm{embj} .201593458$

Cohen, J. I. (2020). Herpesvirus latency. J. Clin. Invest. 130, 3361-3369. doi: $10.1172 / \mathrm{JCI} 136225$ 
Cruz-Muñoz, M. E., and Fuentes-Pananá, E. M. (2018). Beta and Gamma Human Herpesviruses: Agonistic and Antagonistic Interactions with the Host Immune System. Front. Microbiol. 8 (2521), 1-20. doi: 10.3389/fmicb.2017.02521

Cuchet-Lourenço, D., Anderson, G., Sloan, E., Orr, A., and Everett, R. D. (2013). The viral ubiquitin ligase ICP0 is neither sufficient nor necessary for degradation of the cellular DNA sensor IFI16 during herpes simplex virus 1 infection. J. Virol. 87, 13422-13432. doi: 10.1128/JVI.02474-13

Davison, A. J., Eberle, R., Ehlers, B., Hayward, G. S., Mcgeoch, D. J., Minson, A. C., et al. (2009). The order Herpesvirales. Arch. Virol. 154, 171-177. doi: 10.1007/ s00705-008-0278-4

Defilippis, V. R., Alvarado, D., Sali, T., Rothenburg, S., and Früh, K. (2010). Human Cytomegalovirus Induces the Interferon Response via the DNA Sensor ZBP1. J. Virol. 84, 585-598. doi: 10.1128/JVI.01748-09

Dell'oste, V., Gatti, D., Gugliesi, F., De Andrea, M., Bawadekar, M., Lo Cigno, I., et al. (2014). Innate nuclear sensor IFI16 translocates into the cytoplasm during the early stage of in vitro human cytomegalovirus infection and is entrapped in the egressing virions during the late stage. J. Virol. 88, 6970-6982. doi: 10.1128/ JVI.00384-14

Dempsey, A., and Bowie, A. G. (2015). Innate immune recognition of DNA: A recent history. Virology, 479-480, 146-152. doi: 10.1016/j.virol.2015.03.013

Deschamps, T., and Kalamvoki, M. (2017). Evasion of the STING DNA-Sensing Pathway by VP11/12 of Herpes Simplex Virus 1. J. Virol. 91, e00535-17. doi: 10.1128/JVI.00535-17

Diner, B. A., Lum, K. K., and Cristea, I. M. (2015). The emerging role of nuclear viral DNA sensors. J. Biol. Chem. 290, 26412-26421. doi: 10.1074/jbc.R115.652289

Du, M., and Chen, Z. J. (2018). DNA-induced liquid phase condensation of cGAS activates innate immune signaling. Science 361, 704-709. doi: 10.1126/ science.aat 1022

Emming, S., and Schroder, K. (2019). Tiered DNA sensors for escalating responses. Science 365, 1375-1376.

Ferguson, B. J., Mansur, D. S., Peters, N. E., Ren, H., and Smith, G. L. (2012). DNA-PK is a DNA sensor for IRF-3-dependent innate immunity. Elife 1, e00047. doi: 10.7554/eLife.00047

Fernandes-Alnemri, T., Yu, J. W., Datta, P., Wu, J., and Alnemri, E. S. (2009). AIM2 activates the inflammasome and cell death in response to cytoplasmic DNA. Nature 458, 509-513. doi: 10.1038/nature07710

Fiola, S., Gosselin, D., Takada, K., and Gosselin, J. (2010). TLR9 contributes to the recognition of EBV by primary monocytes and plasmacytoid dendritic cells. J. Immunol. 185, 3620-3631. doi: 10.4049/jimmunol.0903736

Fu, Y. Z., Su, S., Gao, Y. Q., Wang, P. P., Huang, Z. F., Hu, M. M., et al. (2017). Human Cytomegalovirus Tegument Protein UL82 Inhibits STING-Mediated Signaling to Evade Antiviral Immunity. Cell Host Microbe 21, 231-243. doi: 10.1016/j.chom.2017.01.001

Fu, Y. Z., Guo, Y., Zou, H. M., Su, S., Wang, S. Y., Yang, Q., et al. (2019). Human cytomegalovirus protein UL42 antagonizes cGAS/MITA-mediated innate antiviral response. PloS Pathog. 15, e1007691. doi: 10.1371/journal.ppat.1007691

Gao, P., Ascano, M., Wu, Y., Barchet, W., Gaffney, B. L., Zillinger, T., et al. (2013). Cyclic $\left[\mathrm{G}\left(2^{\prime}, 5^{\prime}\right) \mathrm{pA}\left(3^{\prime}, 5^{\prime}\right) \mathrm{p}\right]$ is the metazoan second messenger produced by DNA-activated cyclic GMP-AMP synthase. Cell 153, 1094-1107. doi: 10.1016/ j.cell.2013.04.046

Goubau, D., Deddouche, S., and Reis E Sousa, C. (2013). Cytosolic sensing of viruses. Immunity 38, 855-869. doi: 10.1016/j.immuni.2013.05.007

Hafez, A. Y., and Luftig, M. A. (2017). Characterization of the EBV-Induced Persistent DNA Damage Response. Viruses 9, (12), 366. doi: 10.3390/v9120366

Hau, P. M., and Tsao, S. W. (2017). Epstein-Barr Virus Hijacks DNA Damage Response Transducers to Orchestrate Its Life Cycle. Viruses 9, 341. doi: 10.3390/v9110341

Hemmi, H., Takeuchi, O., Kawai, T., Kaisho, T., Sato, S., Sanjo, H., et al. (2000). A Toll-like receptor recognizes bacterial DNA. Nature 408, 740-745. doi: $10.1038 / 35047123$

Heming, J. D., Conway, J. F., and Homa, F. L. (2017). Herpesvirus Capsid Assembly and DNA Packaging. Adv. Anat. Embryol. Cell. Biol. 223, 119-142.

Hew, K., Dahlroth, S. L., Pan, L. X., Cornvik, T., and Nordlund, P. (2015). VP22 core domain from Herpes simplex virus 1 reveals a surprising structural conservation in both the Alpha- and Gammaherpesvirinae subfamilies. J. Gen. Virol. 96, 1436-1445. doi: 10.1099/vir.0.000078

Horan, K. A., Hansen, K., Jakobsen, M. R., Holm, C. K., Søby, S., Unterholzner, L., et al. (2013). Proteasomal degradation of herpes simplex virus capsids in macrophages releases DNA to the cytosol for recognition by DNA sensors. J. Immunol. 190, 2311-2319. doi: 10.4049/jimmunol.1202749

Hornung, V., Ablasser, A., Charrel-Dennis, M., Bauernfeind, F., Horvath, G., Caffrey, D. R., et al. (2009). AIM2 recognizes cytosolic dsDNA and forms a caspase-1-activating inflammasome with ASC. Nature 458, 514-518. doi: 10.1038/nature07725

Huang, Y., Liu, L., Ma, D., Liao, Y., Lu, Y., Huang, H., et al. (2017a). Human cytomegalovirus triggers the assembly of AIM2 inflammasome in THP-1derived macrophages. J. Med. Virol. 89, 2188-2195. doi: 10.1002/jmv.24846

Huang, Y., Ma, D., Huang, H., Lu, Y., Liao, Y., Liu, L., et al. (2017b). Interaction between HCMV pUL83 and human AIM2 disrupts the activation of the AIM2 inflammasome. Virol. J. 14, 34-34. doi: 10.1186/s12985-016-0673-5

Huang, J., You, H., Su, C., Li, Y., Chen, S., and Zheng, C. (2018). Herpes Simplex Virus 1 Tegument Protein VP22 Abrogates cGAS/STING-Mediated Antiviral Innate Immunity. J. Virol. 92, e00841-e00818. doi: 10.1128/JVI.00841-18

Huang, Z. F., Zou, H. M., Liao, B. W., Zhang, H. Y., Yang, Y., Fu, Y. Z., et al. (2018). Human Cytomegalovirus Protein UL31 Inhibits DNA Sensing of cGAS to Mediate Immune Evasion. Cell Host Microbe 24, 69-80.e64. doi: 10.1016/ j.chom.2018.05.007

Isaacs, A., Cox, R. A., and Rotem, Z. (1963). Foreign nucleic acids as the stimulus to make interferon. Lancet 2, 113-116. doi: 10.1016/S0140-6736(63)92585-6

Ishikawa, H., and Barber, G. N. (2008). STING is an endoplasmic reticulum adaptor that facilitates innate immune signalling. Nature 455, 674-678.

Iversen, M. B., Ank, N., Melchjorsen, J., and Paludan, S. R. (2010). Expression of type III interferon (IFN) in the vaginal mucosa is mediated primarily by dendritic cells and displays stronger dependence on NF-kappaB than type I IFNs. J. Virol. 84, 4579-4586. doi: 10.1128/JVI.02591-09

Iwakiri, D., Zhou, L., Samanta, M., Matsumoto, M., Ebihara, T., Seya, T., et al. (2009). Epstein-Barr virus (EBV)-encoded small RNA is released from EBVinfected cells and activates signaling from Toll-like receptor 3. J. Exp. Med. 206, 2091-2099. doi: 10.1084/jem.20081761

Jiang, H., Xue, X., Panda, S., Kawale, A., Hooy, R. M., Liang, F., et al. (2019). Chromatin-bound cGAS is an inhibitor of DNA repair and hence accelerates genome destabilization and cell death. EMBO J. 38, e102718. doi: 10.15252/ embj.2019102718

Johnson, K. E., Chikoti, L., and Chandran, B. (2013). Herpes simplex virus 1 infection induces activation and subsequent inhibition of the IFI16 and NLRP3 inflammasomes. J. Virol. 87, 5005-5018. doi: 10.1128/JVI.00082-13

Johnson, K. E., Bottero, V., Flaherty, S., Dutta, S., Singh, V. V., and Chandran, B. (2014). IFI16 Restricts HSV-1 Replication by Accumulating on the HSV-1 Genome, Repressing HSV-1 Gene Expression, and Directly or Indirectly Modulating Histone Modifications. PloS Pathog. 10, e1004503. doi: 10.1371/ journal.ppat.1004503

Jønsson, K. L., Laustsen, A., Krapp, C., Skipper, K. A., Thavachelvam, K., Hotter, D., et al. (2017). IFI16 is required for DNA sensing in human macrophages by promoting production and function of cGAMP. Nat. Commun. 8, 14391. doi: 10.1038/ncomms14391

Kalamvoki, M., and Roizman, B. (2014). HSV-1 degrades, stabilizes, requires, or is stung by STING depending on ICP0, the US3 protein kinase, and cell derivation. Proc. Natl. Acad. Sci. 111, E611-E617. doi: 10.1073/pnas.1323414111

Kawai, T., and Akira, S. (2011). Toll-like receptors and their crosstalk with other innate receptors in infection and immunity. Immunity 34, 637-650. doi: 10.1016/j.immuni.2011.05.006

Kerur, N., Veettil, M. V., Sharma-Walia, N., Bottero, V., Sadagopan, S., Otageri, P., et al. (2011). IFI16 acts as a nuclear pathogen sensor to induce the inflammasome in response to Kaposi Sarcoma-associated herpesvirus infection. Cell Host Microbe 9, 363-375. doi: 10.1016/j.chom.2011.04.008

Kim, T., Pazhoor, S., Bao, M., Zhang, Z., Hanabuchi, S., Facchinetti, V., et al. (2010). Aspartate-glutamate-alanine-histidine box motif (DEAH)/RNA helicase A helicases sense microbial DNA in human plasmacytoid dendritic cells. Proc. Natl. Acad. Sci. U. S. A. 107, 15181-15186. doi: 10.1073/pnas.1006539107

Knipe, D. M., and Howley, P. (2013). Fields Virology (Philadelphia: Wolters Kluwer Health).

Knipe, D. M. (2015). Nuclear sensing of viral DNA, epigenetic regulation of herpes simplex virus infection, and innate immunity. Virology 479-480, 153-159. doi: 10.1016/j.virol.2015.02.009

Kondo, T., Kobayashi, J., Saitoh, T., Maruyama, K., Ishii, K. J., Barber, G. N., et al. (2013). DNA damage sensor MRE11 recognizes cytosolic double-stranded 
DNA and induces type I interferon by regulating STING trafficking. Proc. Natl. Acad. Sci. U. S. A. 110, 2969-2974. doi: 10.1073/pnas.1222694110

Krug, A., Luker, G. D., Barchet, W., Leib, D. A., Akira, S., and Colonna, M. (2004). Herpes simplex virus type 1 activates murine natural interferon-producing cells through toll-like receptor 9. Blood 103, 1433-1437. doi: 10.1182/blood2003-08-2674

Kujirai, T., Zierhut, C., Takizawa, Y., Kim, R., Negishi, L., Uruma, N., et al. (2020). Structural basis for the inhibition of cGAS by nucleosomes. Science 370, 455458. doi: $10.1126 /$ science.abd0237

Kumari, P., Saha, I., Narayanan, A., Narayanan, S., Takaoka, A., Kumar, N. S., et al. (2017). Essential role of HCMV deubiquitinase in promoting oncogenesis by targeting anti-viral innate immune signaling pathways. Cell Death Dis. 8, e3078. doi: 10.1038/cddis.2017.461

Lee, H.-C., Chathuranga, K., and Lee, J.-S. (2019). Intracellular sensing of viral genomes and viral evasion. Exp. Mol. Med. 51, 1-13. doi: 10.1038/s12276-0190299-y

Lees-Miller, S. P., Long, M. C., Kilvert, M. A., Lam, V., Rice, S. A., and Spencer, C. A. (1996). Attenuation of DNA-dependent protein kinase activity and its catalytic subunit by the herpes simplex virus type 1 transactivator ICP0. J. Virol. 70, 7471-7477. doi: 10.1128/JVI.70.11.7471-7477.1996

Leoni, V., Gianni, T., Salvioli, S., and Campadelli-Fiume, G. (2012). Herpes simplex virus glycoproteins $\mathrm{gH} / \mathrm{gL}$ and $\mathrm{gB}$ bind Toll-like receptor 2 , and soluble gH/gL is sufficient to activate NF- $\mathrm{KB}$. J. Virol. 86, 6555-6562. doi: 10.1128/JVI.00295-12

Li, T., Diner, B. A., Chen, J., and Cristea, I. M. (2012). Acetylation modulates cellular distribution and DNA sensing ability of interferon-inducible protein IFI16. Proc. Natl. Acad. Sci. 109, 10558-10563. doi: 10.1073/pnas.1203447109

Li, T., Chen, J., and Cristea, I. M. (2013). Human cytomegalovirus tegument protein pUL83 inhibits IFI16-mediated DNA sensing for immune evasion. Cell Host Microbe 14, 591-599. doi: 10.1016/j.chom.2013.10.007

Li, X. D., Wu, J., Gao, D., Wang, H., Sun, L., and Chen, Z. J. (2013). Pivotal roles of cGAS-cGAMP signaling in antiviral defense and immune adjuvant effects. Science 341, 1390-1394. doi: 10.1126/science. 1244040

Lilley, C. E., Chaurushiya, M. S., Boutell, C., Everett, R. D., and Weitzman, M. D. (2011). The Intrinsic Antiviral Defense to Incoming HSV-1 Genomes Includes Specific DNA Repair Proteins and Is Counteracted by the Viral Protein ICP0. PloS Pathog. 7, e1002084. doi: 10.1371/journal.ppat.1002084

Lima, G. K., Zolini, G. P., Mansur, D. S., Freire Lima, B. H., Wischhoff, U., Astigarraga, R. G., et al. (2010). Toll-like receptor (TLR) 2 and TLR9 expressed in trigeminal ganglia are critical to viral control during herpes simplex virus 1 infection. Am. J. Pathol. 177, 2433-2445. doi: 10.2353/ajpath.2010.100121

Lio, C. W., Mcdonald, B., Takahashi, M., Dhanwani, R., Sharma, N., Huang, J., et al. (2016). cGAS-STING Signaling Regulates Initial Innate Control of Cytomegalovirus Infection. J. Virol. 90, 7789-7797. doi: 10.1128/JVI.01040-16

Liu, H., Zhang, H., Wu, X., Ma, D., Wu, J., Wang, L., et al. (2018). Nuclear cGAS suppresses DNA repair and promotes tumorigenesis. Nature 563, 131-136. doi: 10.1038/s41586-018-0629-6

Liu, Q., Rao, Y., Tian, M., Zhang, S., and Feng, P. (2019). Modulation of Innate Immune Signaling Pathways by Herpesviruses. Viruses 11, 572. doi: 10.3390/ v11060572

Luecke, S., Holleufer, A., Christensen, M. H., Jonsson, K. L., Boni, G. A., Sorensen, L. K., et al. (2017). cGAS is activated by DNA in a length-dependent manner. EMBO Rep. 18, 1707-1715. doi: 10.15252/embr.201744017

Lu, J., Tang, M., Li, H., Xu, Z., Weng, X., Li, J., et al. (2016). EBV-LMP1 suppresses the DNA damage response through DNA-PK/AMPK signaling to promote radioresistance in nasopharyngeal carcinoma. Cancer Lett. 380, 191-200.

Lund, J., Sato, A., Akira, S., Medzhitov, R., and Iwasaki, A. (2003). Toll-like receptor 9-mediated recognition of Herpes simplex virus-2 by plasmacytoid dendritic cells. J. Exp. Med. 198, 513-520. doi: 10.1084/jem.20030162

Ma, Y., and He, B. (2014). Recognition of herpes simplex viruses: toll-like receptors and beyond. J. Mol. Biol. 426, 1133-1147. doi: 10.1016/ j.jmb.2013.11.012

Ma, Z., Jacobs, S. R., West, J. A., Stopford, C., Zhang, Z., Davis, Z., et al. (2015). Modulation of the cGAS-STING DNA sensing pathway by gammaherpesviruses. Proc. Natl. Acad. Sci. 112, E4306-E4315. doi: 10.1073/ pnas. 1503831112

Ma, Z., Ni, G., and Damania, B. (2018). Innate Sensing of DNA Virus Genomes. Annu. Rev. Virol. 5, 341-362. doi: 10.1146/annurev-virology-092917-043244
Maruzuru, Y., Ichinohe, T., Sato, R., Miyake, K., Okano, T., Suzuki, T., et al. (2018). Herpes Simplex Virus 1 VP22 Inhibits AIM2-Dependent Inflammasome Activation to Enable Efficient Viral Replication. Cell Host Microbe 23, 254-265, e257. doi: 10.1016/j.chom.2017.12.014

Mboko, W. P., Mounce, B. C., Wood, B. M., Kulinski, J. M., Corbett, J. A., and Tarakanova, V. L. (2012). Coordinate regulation of DNA damage and type I interferon responses imposes an antiviral state that attenuates mouse gammaherpesvirus type 68 replication in primary macrophages. J. Virol. 86, 6899-6912. doi: 10.1128/JVI.07119-11

Merkl, P. E., and Knipe, D. M. (2019). Role for a Filamentous Nuclear Assembly of IFI16, DNA, and Host Factors in Restriction of Herpesviral Infection. mBio 10, e02621-18. doi: 10.1128/mBio.02621-18

Michalski, S., De Oliveira Mann, C. C., Stafford, C., Witte, G., Bartho, J., Lammens, K., et al. (2020). Structural basis for sequestration and autoinhibition of cGAS by chromatin. Nature 587, 678-682. doi: 10.1038/s41586-020-2748-0

Mogensen, T. H. (2009). Pathogen recognition and inflammatory signaling in innate immune defenses. Clin. Microbiol. Rev. 22, 240-273. doi: 10.1128/ CMR.00046-08

Orzalli, M. H., Deluca, N. A., and Knipe, D. M. (2012). Nuclear IFI16 induction of IRF-3 signaling during herpesviral infection and degradation of IFI16 by the viral ICP0 protein. Proc. Natl. Acad. Sci. 109, E3008-E3017. doi: 10.1073/ pnas. 1211302109

Orzalli, M. H., Broekema, N. M., Diner, B. A., Hancks, D. C., Elde, N. C., Cristea, I. M., et al. (2015). cGAS-mediated stabilization of IFI16 promotes innate signaling during herpes simplex virus infection. Proc. Natl. Acad. Sci. U.S.A. 112, E1773-E1781. doi: 10.1073/pnas.1424637112

Orzalli, M. H., Broekema, N. M., and Knipe, D. M. (2016). Relative Contributions of Herpes Simplex Virus 1 ICP0 and vhs to Loss of Cellular IFI16 Vary in Different Human Cell Types. J. Virol. 90, 8351-8359. doi: 10.1128/JVI.0093916

Paijo, J., Döring, M., Spanier, J., Grabski, E., Nooruzzaman, M., Schmidt, T., et al. (2016). cGAS Senses Human Cytomegalovirus and Induces Type I Interferon Responses in Human Monocyte-Derived Cells. PloS Pathog. 12, e1005546. doi: 10.1371/journal.ppat.1005546

Paludan, S. R., and Bowie, A. G. (2013). Immune sensing of DNA. Immunity 38, 870-880. doi: 10.1016/j.immuni.2013.05.004

Paludan, S. R., Bowie, A. G., Horan, K. A., and Fitzgerald, K. A. (2011). Recognition of herpesviruses by the innate immune system. Nat. Rev. Immunol. 11, 143-154. doi: 10.1038/nri2937

Paludan, S. R. (2015). Activation and regulation of DNA-driven immune responses. Microbiol. Mol. Biol. Rev. MMBR 79, 225-241. doi: 10.1128/ MMBR.00061-14

Pan, S., Liu, X., Ma, Y., Cao, Y., and He, B. (2018). Herpes Simplex Virus $1 \gamma(1) 34.5$ Protein Inhibits STING Activation That Restricts Viral Replication. J. Virol. 92, e01015-e01018. doi: 10.1128/JVI.01015-18

Parkinson, J., Lees-Miller, S. P., and Everett, R. D. (1999). Herpes simplex virus type 1 immediate-early protein vmw110 induces the proteasome-dependent degradation of the catalytic subunit of DNA-dependent protein kinase. J. Virol. 73, 650-657. doi: 10.1128/JVI.73.1.650-657.1999

Pathare, G. R., Decout, A., Glück, S., Cavadini, S., Makasheva, K., Hovius, R., et al. (2020). Structural mechanism of cGAS inhibition by the nucleosome. Nature 587, 668-672. doi: 10.1038/s41586-020-2750-6

Pisano, G., Roy, A., Ahmed Ansari, M., Kumar, B., Chikoti, L., and Chandran, B. (2017). Interferon- $\gamma$-inducible protein 16 (IFI16) is required for the maintenance of Epstein-Barr virus latency. Virol. J. 14, 221. doi: 10.1186/ s12985-017-0891-5

Rasmussen, S. B., Sørensen, L. N., Malmgaard, L., Ank, N., Baines, J. D., Chen, Z. J., et al. (2007). Type I interferon production during herpes simplex virus infection is controlled by cell-type-specific viral recognition through Toll-like receptor 9 , the mitochondrial antiviral signaling protein pathway, and novel recognition systems. J. Virol. 81, 13315-13324. doi: 10.1128/JVI.01167-07

Reinert, L. S., Lopušná, K., Winther, H., Sun, C., Thomsen, M. K., Nandakumar, R., et al. (2016). Sensing of HSV-1 by the cGAS-STING pathway in microglia orchestrates antiviral defence in the CNS. Nat. Commun. 7, 13348. doi: $10.1038 /$ ncomms 13348

Roy, A., Dutta, D., Iqbal, J., Pisano, G., Gjyshi, O., Ansari, M. A., et al. (2016). Nuclear Innate Immune DNA Sensor IFI16 Is Degraded during Lytic Reactivation of Kaposi's Sarcoma-Associated Herpesvirus (KSHV): Role of 
IFI16 in Maintenance of KSHV Latency. J. Virol. 90, 8822-8841. doi: 10.1128/ JVI.01003-16

Roy, A., Ghosh, A., Kumar, B., and Chandran, B. (2019). IFI16, a nuclear innate immune DNA sensor, mediates epigenetic silencing of herpesvirus genomes by its association with H3K9 methyltransferases SUV39H1 and GLP. eLife 8, e49500. doi: 10.7554/eLife.49500

Speck, S. H., and Ganem, D. (2010). Viral latency and its regulation: lessons from the gamma-herpesviruses. Cell Host Microbe 8, 100-115. doi: 10.1016/ j.chom.2010.06.014

Stratmann, S. A., Morrone, S. R., Van Oijen, A. M., and Sohn, J. (2015). The innate immune sensor IFI16 recognizes foreign DNA in the nucleus by scanning along the duplex. eLife 4, e11721-e11721. doi: 10.7554/eLife.11721

$\mathrm{Su}, \mathrm{C}$., and Zheng, C. (2017). Herpes Simplex Virus 1 Abrogates the cGAS/STINGMediated Cytosolic DNA-Sensing Pathway via Its Virion Host Shutoff Protein, UL41. J. Virol. 91, e02414-e02416. doi: 10.1128/JVI.02414-16

Sun, L., Wu, J., Du, F., Chen, X., and Chen, Z. J. (2013). Cyclic GMP-AMP synthase is a cytosolic DNA sensor that activates the type I interferon pathway. Science 339, 786-791. doi: 10.1126/science.1232458

Sun, C., Luecke, S., Bodda, C., Jønsson, K. L., Cai, Y., Zhang, B. C., et al. (2019). Cellular Requirements for Sensing and Elimination of Incoming HSV-1 DNA and Capsids. J. Interferon Cytokine Res. 39, 191-204. doi: 10.1089/jir.2018.0141

Takaoka, A., Wang, Z., Choi, M. K., Yanai, H., Negishi, H., Ban, T., et al. (2007). DAI (DLM-1/ZBP1) is a cytosolic DNA sensor and an activator of innate immune response. Nature 448, 501-505. doi: 10.1038/nature06013

Tanaka, Y., and Chen, Z. J. (2012). STING specifies IRF3 phosphorylation by TBK1 in the cytosolic DNA signaling pathway. Sci. Signal 5, ra20. doi: 10.1126/ scisignal.2002521

Unterholzner, L., Keating, S. E., Baran, M., Horan, K. A., Jensen, S. B., Sharma, S., et al. (2010). IFI16 is an innate immune sensor for intracellular DNA. Nat. Immunol. 11, 997-1004. doi: 10.1038/ni.1932

Unterholzner, L. (2013). The interferon response to intracellular DNA: why so many receptors? Immunobiology 218, 1312-1321. doi: 10.1016/j.imbio.2013.07.007

Upton, J. W., Kaiser, W. J., and Mocarski, E. S. (2012). DAI/ZBP1/DLM-1 complexes with RIP3 to mediate virus-induced programmed necrosis that is targeted by murine cytomegalovirus vIRA. Cell Host Microbe 11, 290-297. doi: 10.1016/j.chom.2012.01.016

Vogt, D., Zaver, S., Ranjan, A., Dimaio, T., Gounder, A. P., Smith, J. G., et al. (2020). STING is dispensable during KSHV infection of primary endothelial cells. Virology 540, 150-159. doi: 10.1016/j.virol.2019.11.012

Volkman, H. E., Cambier, S., Gray, E. E., and Stetson, D. B. (2019). Tight nuclear tethering of cGAS is essential for preventing autoreactivity. eLife 8, e47491. doi: 10.7554/eLife.47491

Wang, L., Wen, M., and Cao, X. (2019). Nuclear hnRNPA2B1 initiates and amplifies the innate immune response to DNA viruses. Science 365. doi: 10.1126/science.aav0758

West, J. A., Gregory, S. M., Sivaraman, V., Su, L., and Damania, B. (2011). Activation of plasmacytoid dendritic cells by Kaposi's sarcoma-associated herpesvirus. J. Virol. 85, 895-904. doi: 10.1128/JVI.01007-10

West, J. A., Gregory, S. M., and Damania, B. (2012). Toll-like receptor sensing of human herpesvirus infection. Front. Cell. Infect. Microbiol. 2, 122-122. doi: 10.3389/fcimb.2012.00122

West, A. P., Khoury-Hanold, W., Staron, M., Tal, M. C., Pineda, C. M., Lang, S. M., et al. (2015). Mitochondrial DNA stress primes the antiviral innate immune response. Nature 520, 553-557. doi: 10.1038/nature14156
Wu, Y., and Li, S. (2020). Role of Post-Translational Modifications of cGAS in Innate Immunity. Int. J. Mol. Sci. 21, 7842. doi: 10.3390/ijms21217842

Wu, J., Sun, L., Chen, X., Du, F., Shi, H., Chen, C., et al. (2013). Cyclic GMP-AMP is an endogenous second messenger in innate immune signaling by cytosolic DNA. Science 339, 826-830. doi: 10.1126/science.1229963

Wu, J.-J., Li, W., Shao, Y., Avey, D., Fu, B., Gillen, J., et al. (2015). Inhibition of cGAS DNA Sensing by a Herpesvirus Virion Protein. Cell Host Microbe 18, 333-344. doi: 10.1016/j.chom.2015.07.015

Wu, J., Dobbs, N., Yang, K., and Yan, N. (2020). Interferon-Independent Activities of Mammalian STING Mediate Antiviral Response and Tumor Immune Evasion. Immunity 53, 115-126.e115. doi: 10.1016/j.immuni.2020.06.009

Yamashiro, L. H., Wilson, S. C., Morrison, H. M., Karalis, V., Chung, J.-Y. J., Chen, K. J., et al. (2020). Interferon-independent STING signaling promotes resistance to HSV-1 in vivo. Nat. Commun. 11, 3382. doi: 10.1038/s41467-020-17156-x

Yang, L., Wang, M., Cheng, A., Yang, Q., Wu, Y., Jia, R., et al. (2019). Innate Immune Evasion of Alphaherpesvirus Tegument Proteins. Front. Immunol. 10, 2196. doi: 10.3389/fimmu.2019.02196

You, H., Zheng, S., Huang, Z., Lin, Y., Shen, Q., and Zheng, C. (2019). Herpes Simplex Virus 1 Tegument Protein UL46 Inhibits TANK-Binding Kinase 1Mediated Signaling. mBio 10, e00919-19. doi: 10.1128/mBio.00919-19

Zhang, X., Brann, T. W., Zhou, M., Yang, J., Oguariri, R. M., Lidie, K. B., et al. (2011). Cutting edge: Ku70 is a novel cytosolic DNA sensor that induces type III rather than type I IFN. J. Immunol. (Baltimore Md. 1950) 186, 4541-4545. doi: 10.4049/jimmunol.1003389

Zhang, X., Wu, J., Du, F., Xu, H., Sun, L., Chen, Z., et al. (2014). The cytosolic DNA sensor cGAS forms an oligomeric complex with DNA and undergoes switchlike conformational changes in the activation loop. Cell Rep. 6, 421-430. doi: 10.1016/j.celrep.2014.01.003

Zhang, G., Chan, B., Samarina, N., Abere, B., Weidner-Glunde, M., Buch, A., et al. (2016). Cytoplasmic isoforms of Kaposi sarcoma herpesvirus LANA recruit and antagonize the innate immune DNA sensor cGAS. Proc. Natl. Acad. Sci. 113, E1034-E1043. doi: 10.1073/pnas.1516812113

Zhang, J., Zhao, J., Xu, S., Li, J., He, S., Zeng, Y., et al. (2018). Species-Specific Deamidation of cGAS by Herpes Simplex Virus UL37 Protein Facilitates Viral Replication. Cell Host Microbe 24, 234-248.e235. doi: 10.1016/j.chom. 2018.07.004

Zhao, B., Xu, P., Rowlett, C. M., Jing, T., Shinde, O., Lei, Y., et al. (2020). The Molecular Basis of Tight Nuclear Tethering and Inactivation of cGAS. Nature 587, 673-677. doi: 10.1038/s41586-020-2749-z

Zierhut, C., Yamaguchi, N., Paredes, M., Luo, J.-D., Carroll, T., and Funabiki, H. (2019). The Cytoplasmic DNA Sensor cGAS Promotes Mitotic Cell Death. Cell 178, 302-315.e323. doi: 10.1016/j.cell.2019.05.035

Conflict of Interest: The authors declare that the research was conducted in the absence of any commercial or financial relationships that could be construed as a potential conflict of interest.

Copyright $\odot 2021$ Bhowmik and Zhu. This is an open-access article distributed under the terms of the Creative Commons Attribution License (CC BY). The use, distribution or reproduction in other forums is permitted, provided the original author(s) and the copyright owner(s) are credited and that the original publication in this journal is cited, in accordance with accepted academic practice. No use, distribution or reproduction is permitted which does not comply with these terms. 